\title{
Design of Educational Tools Based on Traditional Games for the Improvement of Social and Personal Skills of Primary School Students with Hearing Impairment
}

\author{
Jesús Fernández-Gavira ${ }^{1,2}$, Paola Espada-Goya ${ }^{2}$, Virginia Alcaraz-Rodríguez ${ }^{2,3, *}$ and David Moscoso-Sánchez ${ }^{4}$ (C) \\ 1 Physical Education and Sport Department, University of Seville, 41013 Seville, Spain; jesusfgavira@us.es \\ 2 Research Group "Social Inclusion, Physical Education and Sport, and European Policies in Research", \\ University of Seville, 41013 Seville, Spain; pao.espada@gmail.com \\ 3 Humanities and Education Area, Valencian International University, 46002 Valencia, Spain \\ 4 Department of Social Sciences, Philosophy, Geography and Translation and Interpretation, University of \\ Cordoba, 14071 Cordova, Spain; dmoscoso@uco.es \\ * Correspondence: virginia.alcaraz@campusviu.es
}

Citation: Fernández-Gavira, J. Espada-Goya, P.; Alcaraz-Rodríguez, V.; Moscoso-Sánchez, D. Design of Educational Tools Based on Traditional Games for the Improvement of Social and Personal Skills of Primary School Students with Hearing Impairment. Sustainability 2021, 13, 12644. https: / / doi.org/10.3390/su132212644

Academic Editors: Víctor Abella García, Roberto Baelo, Sheila García-Martín and Mario Grande-de-Prado

Received: 26 October 2021 Accepted: 12 November 2021 Published: 16 November 2021

Publisher's Note: MDPI stays neutral with regard to jurisdictional claims in published maps and institutional affiliations.

Copyright: (c) 2021 by the authors. Licensee MDPI, Basel, Switzerland. This article is an open access article distributed under the terms and conditions of the Creative Commons Attribution (CC BY) license (https:// creativecommons.org/licenses/by/ $4.0 /)$.

\begin{abstract}
The proposed work aims to offer an educational proposal with which to approach the Physical Education class with hearing impaired students through the use of different tools, with special attention to technological ones. These in turn are structured into objectives, materials, organisation, graphic description and a QR code for each game. These codes are linked to different videos hosted on the YouTube platform, in which the explanation of the games, mentioned above, can be visualised graphically using sign language. The whole creative process is described in the article, as well as possible pedagogical applications of the use of the tools created for this purpose in other educational contexts.
\end{abstract}

Keywords: Information Technologies (I.T.); sign language; hearing impairment; traditional games; primary school teaching; inclusive education; physical education

\section{Introduction}

Education is the foundation of a just society, in which opportunities are equal and accessible to all. That is why the use of communication is the fundamental pillar on which this profession is based.

Within the classroom, there are students with different abilities and limitations to which we have the obligation to provide answers. In this way, we will achieve the full development of our students. Within this range of children that we are going to find in the classroom, we are going to make visible those with hearing impairment.

Among the people with oral communication problems are those with hearing impairments. Bravo [1] states that $8 \%$ of the Spanish population has some degree of hearing impairment, that is, more than one million people and, according to the estimated figures of the World Federation of the Deaf people, there are approximately 72 million deaf people worldwide and many more hearing impaired.

The lack of hearing causes that the people naturally develop a gestural language that allows them to communicate with their environment. In order to improve communication in the field of physical education, within formal education in the primary education stage, we have proposed for this work the creation of a didactic tool based on technological resources that can reach the majority of people. We refer to the so-called QR codes linked to didactic videos specifically developed for our proposal, which will be hosted on a YouTube channel.

This tool available to students with hearing impairment in the Physical Education classroom will consist of signing traditional games, thus facilitating contact between peers, 
which will make the reality of this group visible and will awaken in children without hearing impairment the curiosity to learn another language based on body signs.

\subsection{Hearing Impaired}

We live in a society in which the majority of people are hearing, therefore, people with hearing impairments encounter frequent communication barriers that hinder their personal, social and occupational development. Oral language is the main mechanism through which relationships are established between people, and if any of them have difficulties in this area, they will not be able to access information on equal terms [2].

In order to establish fluid communication between people, it is necessary to use a shared language that allows us to access society. Since we are sociable beings who live in groups, we need to have an adequate communication channel in order to achieve effective linguistic, social and cognitive development.

In this sense, it is necessary to distinguish between two concepts. On the one hand, pupils with hypoacusis, identified as those who are able to receive information in an auditory way, even though they have hearing loss. On the other hand, deaf pupils, who are those who, due to their hearing loss, are not able to receive information through the auditory sense [2].

It is necessary to place special emphasis on the correct use of the term, completely eliminating the concept of deaf-mute to refer to all people with hearing impairment, as to date this term is incorrectly used. This is because a deaf person may be able to communicate through oral language as stated by the Spanish Confederation of Deaf People in 2013.

The diversity of hearing within the group of people with deafness is determined by the sound that they are able to perceive. This sound is measured in decibels (dB), establishing a limit within which it is considered a healthy degree of sound that does not exceed $85 \mathrm{~dB}$ during a specific period of time. The hearing threshold refers to the minimum intensity perceived by the ear. From the threshold of hearing loss between $40-70 \mathrm{~dB}$, a delay in language appears which will determine the way we communicate with the pupil. We can say that, from a severe hearing loss of 70-90 dB, the child will find it very difficult to communicate in oral language, so we must look for an alternative means of communication [2].

\subsection{Situation of Deaf People in Spain: State of the Question}

According to the figures provided by the National Statistics Institute (INE) [3], through the Survey on Disability, Personal Autonomy and Situations of Dependency, 138,900 children under the age of 15 suffer from some type of disability. Among the types of disability, deafness is the fifth most important disability in children [3]. Around 15,600 children are deaf (5200 children under 5 years old and 10,400 children between 6 and 15 years old), i.e., 1 in 10 children who have some kind of disability. The deafness of these children is mostly due to perinatal causes, diseases or congenital reasons.

In relation to the technical or economic assistance these children receive from the administration, $57 \%$ receive some kind of help; the rest does not receive it or does not have it. In the case of $76 \%$ of these children, the mother is the main carer, in the rest of the cases, the mother is the main carer in order of relevance of the contracted persons, fathers or grandparents. In $50 \%$ of the cases, these children require a dedication of more than $6 \mathrm{~h}$ a day [3]. A total of $83 \%$ of their main carers cannot consider working outside the home, have seen their professional situation limited or have financial problems.

Regarding their education, $97 \%$ of deaf children are enrolled in compulsory education, which in Spain lasts until the age of 16. Most of them are in a public school $(70 \%)$ and the rest in state-subsidised $(28 \%)$ or private schools $(2 \%)$. More than half of them are enrolled in a mainstream school without any type of personalised support (52\%), which means that they are in a situation of personal destitution, thus limiting their opportunities for personal development and social integration. Only $33 \%$ are in a mainstream school with integration 
and receiving special support and $14 \%$ are in a special education centre or classroom, thus receiving some kind of help, assistance or special attention.

This situation is particularly delicate if we take into consideration that $95 \%$ of children are born into hearing families, where sign language and symbols are unknown. Furthermore, it must be taken into account that in Spain there is only 1 interpreter for every 173 deaf children, which can hinder their development, training and social integration, despite the fact that Law 27/2007, of 23 October, which recognises Spanish sign languages and regulates the means of support for oral communication for deaf, hearing impaired and deaf-blind people, requires a much lower ratio, in line with the European average of 1 interpreter for every 100 deaf children. According to studies such as [4], although sign language alone does not allow for the full development of deaf children, it is true that even low exposure and use of sign language among deaf children has positive effects on written and reading learning.

Although some authors [5-7] believe that inclusion is only achieved when deaf pupils are placed in mainstream classes with hearing pupils and are involved in all aspects of school life, other authors [8], on the other hand, believe that inclusion is only achieved when deaf pupils are placed in mainstream classes with hearing pupils and are involved in all aspects of school life, on the other hand, consider that inclusion can only be achieved when the education of deaf pupils takes place within specialised programmes and separately from hearing pupils, by better addressing their communication and language needs, socialisation and cultural identity.

However, the situation in Spain is somewhat complicated because, although a welfare model prevails, the truth is that the implementation of this model is uneven, given that educational competences are decentralised from the State to the regional administrations, and these devote different public expenditure to the education system and different degrees and types of attention to deaf children of school age.

However, the truth is that it cannot be said that a de facto inclusive education model exists in Spain, as there is still a lack of sufficient means and resources to guarantee it. There are even organisations that criticise the attitude of schools for subtly expelling these children from the education system, given that it requires resources that are not available to attend to them and this often ends up making it difficult to attend to the rest of the children in the classroom.

Be that as it may, it is certain that in Spain, where a model clearly prevails that is insufficiently neglected from the point of view of special education for deaf children, the result is that, after the period of compulsory education, $86 \%$ of these children do not continue studying and, of those who do, more than half of them do not, of those who do, more than half (54\%) go on to non-formal studies (i.e., non-official studies), compared to those who go on to formal studies (i.e., official studies at any level) (38\%), and only $1 \%$ of deaf children end up obtaining a university degree [3].

In this last respect, it is noted that the rural environment is a double handicap for these children, since, while $8 \%$ of deaf children living in large population centres go on to university studies, only $2 \%$ of deaf children living in municipalities of less than 10,000 inhabitants go on to university studies. This may be due to the scarcity of special education centres and disability specialists in rural schools, as well as to the resources allocated by each regional administration to the education system, the model applied by these administrations and other reasons of socio-economic and cultural nature.

\subsection{Inclusive Education}

One of the fundamental pillars for academic success is fluid communication between students and teachers. In addition, it is ideal to have a suitable environment for correct feedback, i.e., for the information to reach the students correctly. We are talking about quiet and calm environments. It is important to take into account the speed and clarity of the discussion in class, as it makes it difficult to access the complete information. Not attending to this correctly may imply that the pupil knows the topics being discussed but, 
on the other hand, the reduction of comprehension, passivity and even the abandonment of children with hearing impairment [9].

Borders et al. [10] emphasised that by developing appropriate communication, hearing impaired pupils will have an equal chance to achieve well academically. Otherwise, the child will feel frustrated and fail at school.

The role of the teacher is important for an inclusive and quality education, so it is essential to know the characteristics of the students. If we are talking about children with hearing impairment, it is necessary to know, among other factors, the diagnosis, early support and to develop good practices with the students [9]. In this sense, the role of the family is fundamental in order to enhance all the child's abilities and they must select the way to communicate effectively with their child. A widespread complaint from families is the lack of guidance and resources. To achieve this, it is essential that both teachers and families work together [10].

\subsection{Sign Language}

According to the Spanish Confederation of Deaf People, sign language is the natural communication system of deaf people through gestures, so it develops mainly the visual aspect. It also has its own grammatical structure, which is different from the spoken language. In order to transmit the message, it is necessary to use hands, arms, trunk and face.

Favouring the correct communication of both hearing and non-hearing students guarantees the correct cognitive development, increases the quality of life and reduces trauma. In short, it guarantees good mental health and an inclusive and quality education. Promoting the teaching of sign language in schools will eliminate possible communication barriers that still exist today. In this way, it will promote the full integration of deaf people into society [11].

It should be mentioned that experts agree on the importance of early acquisition of sign language for the development of deaf children, as it has been shown that the use of sign language has the same neurocognitive benefits for deaf children as the use of oral language for hearing children. However, there is still a tendency to insert them into oralist education, which carries risks during the critical period of language acquisition, with the possible effect on their mental and physical health [12].

It is not a universal language, as one or more languages exist in each country. It has developed naturally over time through contact between users. For many years, this language has been banned, but it has remained alive and its user community has protected and passed on its linguistic heritage from generation to generation. The proposal made in this work uses Spanish sign language (see Figure 1).

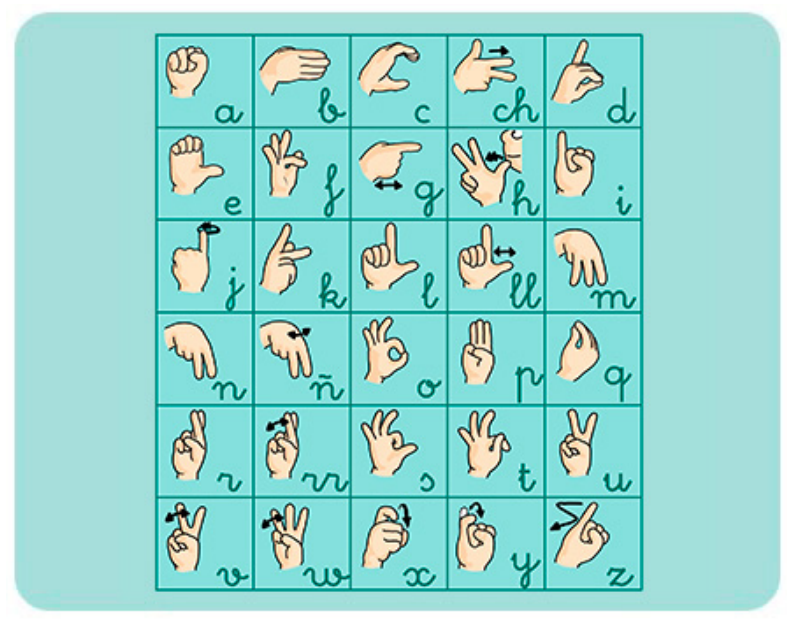

Figure 1. Spanish sign alphabet (BY CCO 3.0.). 
In short, we must bear in mind that not all deaf people communicate with the same sign language. Moreover, not all deaf people communicate in this language, as it depends on many factors, such as the time of onset or the hearing level/rests available to them.

Sign language is not only composed of signs for words or ideas, but also consists of a dactylological alphabet of each individual letter of the alphabet, i.e., each letter has a specific sign. This alphabet was created by hearing people with the aim of immersing them in the oral society. The dactylological alphabet is used to refer to proper names, names of places and people, or to clarify a concept that does not yet have a sign [13].

In the 2018 edition [8] (Figure 2), up to 137 sign languages were counted even taking into account that there are countries in which Sign Language is not recognized as an official language, you could see them in grey color in the previous figure. There are also up to eight families according to the origin of the creation of the language and there is an international sign language [14].

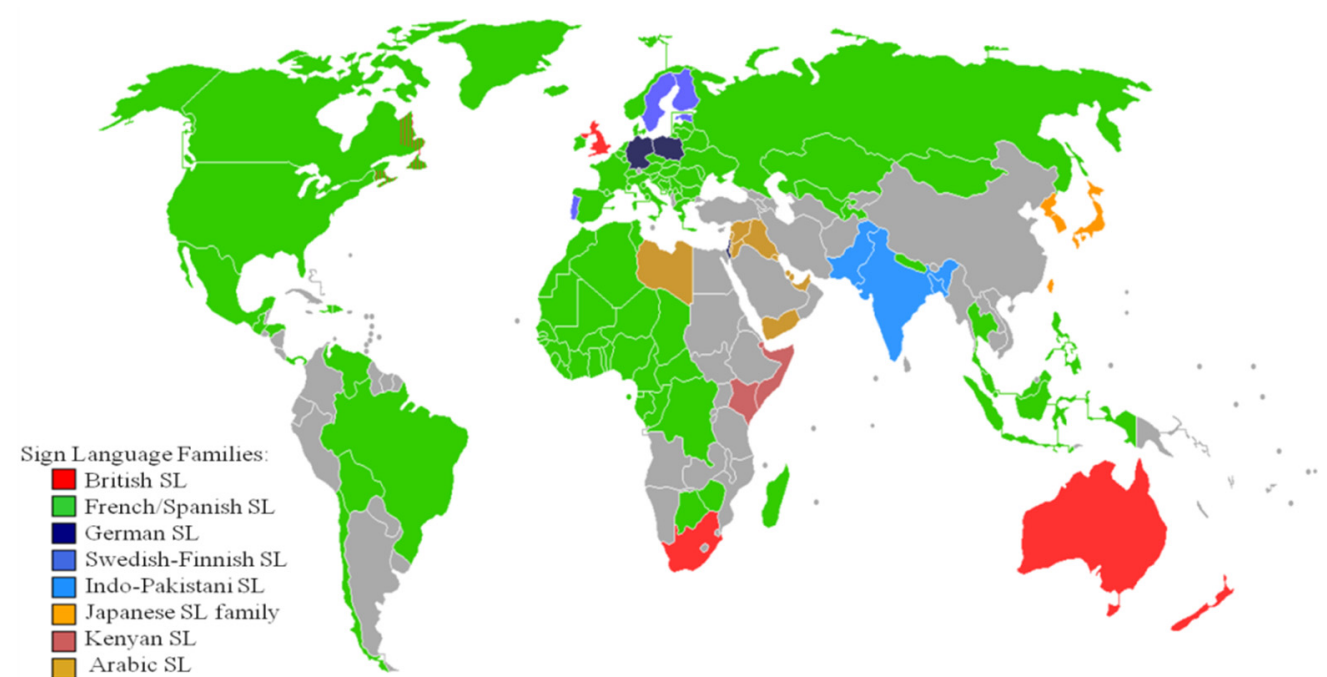

Figure 2. Map of Sign Languages according to origin (Modified from creation by Davius with li-cence BY CCO 1.0.).

\subsection{Deaf Community}

The Deaf Community, as stated the Confederation of Deaf People in 2013, is a linguistic and socio-cultural minority that shares a common language. It is made up of a heterogeneous group of deaf and hearing people where the lack of hearing is not considered a disability, but a way of living and understanding the environment.

Deaf people's culture is not only based on hearing loss, but on a series of values, beliefs and social networks. Therefore, the strength of this community is the diversity of people within it [15].

It is the members of the Deaf Community themselves who have to eradicate the self-definition of the disabled, as there is a tendency to label the Deaf as a person who, in order to belong to an oral society, must be treated and/or cured, through visual and auditory aids, leaving aside the use of their natural language. Therefore, we must balance the positions of power imposed by the majority group, i.e., eliminate the conception that the hearing culture is superior and should not impose the way of educating deaf children, since imposing a type of non-accessible education has had serious consequences on the psychological development of the deaf child. Furthermore, deaf people should be recognised as a cultural and linguistic minority, i.e., they are those who share a language, customs and traditions of their own that although they are a minority within society, their rights should be respected [16].

In spite of efforts to change the self-labelling of deaf people, institutions such as the WHO and UNESCO continue to use the term disability, although they emphasise the empowerment of deaf people with the aim of eliminating social marginalisation. This 
article reflects the importance of belonging to a deaf community, as it implies an increase in self-esteem, in short, an improvement in the psychological problems suffered by the group [17].

\subsection{Physical Education and Play}

The discovery of students' motor qualities and skills is given by the development of Physical Education in the school stage. In it, individual and collective situations are put into practice which allow them to adapt to different contexts. We can say that Physical Education, as well as providing an educational value, allows pupils to interact both with the environment and with their peers. In addition, it enables them to solve problems in different motor situations [18].

Due to the importance of peer interaction in Physical Education, we must highlight the play. Play "is a joyful, pleasurable and free activity that develops within itself, without responding to extrinsic goals, and involves the whole person, providing them with means for expression, communication and learning" [19].

Through play, children develop diverse capacities, such as physical, organic, articular and muscular capacities, allowing the development of motor skills, technical and tactical skills. They acquire positive social skills and it helps them to know themselves and to understand the world around them. They also learn to express their feelings and to respect rules and values. In other words, play is fundamental for the integral development of pupils [20].

Along the same lines, Lavega [21] described that games have a series of characteristics: voluntariness, referring to the freedom in the participation of students; fun, whose purpose is to enjoy while it is being played; spontaneity, focusing thought on the game itself; free, it should be an activity that does not require anything in return, i.e., it is not about winning or losing, but about enjoying playing; uncertain, in which the final result is not important; ambivalent, with great emotional involvement; committed, it develops attitudes such as commitment and responsibility when carrying out the task; creative, imaginative and serious, since when the child is involved in the game he/she makes this the most important thing for him/her at that moment; and it is regulated, this implies that all participants are at the same level (pp. 12-14).

In the area of Physical Education, games are an adaptation of the cultural and social expression of our environment, hence, the importance of rescuing traditional games that are a link between children's culture and school [22].

According to Cruz [23], traditional games are "ludic practices whose rules have generally been learned through oral transmission" (p. 55). Through them, the customs and traditions of the land are revealed and they have their own characteristics depending on the geographical area and the historical moment in which we find ourselves.

Because of all this, it is perfectly understandable that play is precisely the most integrative tool that allows deaf and hearing children to interact in a natural and intuitive way.

\subsection{Traditional Games}

There is no doubt that the game encourages the establishment of interpersonal relationships among peers, as the pupils, depending on the game to be played, will establish contact with other players, as well as sharing space, time and materials [24].

With regard to the organisation of pupils in games, we can find those that are organized according to participation and communication [25].

This classification, due to the social characteristics implicit in them and the objective they are intended to achieve, divides the games into four categories: individual or selfimprovement, opposition, cooperation and cooperation-opposition.

In this section, we are going to base the organisation of the following traditional games on the category mentioned above, although we have made a modification to group 
individual and opposition games together. Because the difference between them is the existence or not of a rival.

\subsubsection{Individual or Self-Improvement/Opposition}

The first category refers to the individual competition of each student, that is to say, they carry out the activity independently in which the objective depends only on the student who executes it. They do not interact with other classmates, although they share the same space. Examples of such games are, individual skipping rope, or the hula hoop. Opposition games are those in which a pupil has to compete with other pupil/s, i.e., there is an individual competition as the objective depends on the pupil him/herself. The aim of these games is individual achievement. They interact with each other and participate simultaneously. Other examples of traditional games that follow the same classification are the following:the badges and stone paper scissors game.

\subsubsection{Cooperative}

In this classification there is no opposition, i.e., they do not compete with any rival, but with the help of their companions they have to reach a common good. They interact with each other and participate simultaneously. We suggest several examples of games with the same structure: the three-legged race, the skipping rope, the blind man's hen, and the wild wheelbarrow game.

\subsubsection{Cooperation-Opposition}

This refers to those games in which the organisation of the pupils is composed of several pupils in teams, who have to compete with each other. The aim is group achievement. Other examples of games that follow the same classification are the following: hide and seek game, tug-of-war, cat and mouse.

\subsection{Information and Communication Technologies (ICT)}

Today, we live in a knowledge society, in which we can obtain all kinds of information immediately through the use of technological tools. The use of the so-called Information and Communication Technologies (ICT) has produced modifications in society in general, having a great impact on school education itself [26].

For many decades, education was perpetuated, especially since the industrial revolution, it maintained the same methodology, it was aimed at the same profile of students, obtaining as results individuals similar to their own parents; however, currently due to social advances, which have manifested themselves, among other things in greater availability of free time to spend with the family for example, the education system has had to adapt to respond to these new times, also using new communication methodologies with which to bring the message to the students. Thus, classrooms have become a place of coexistence for very different individuals where ICT have proved to be fundamental for the individual development of people regardless of their mental, physical or sensory abilities [27].

The use of ICT is increasingly present in the field of education, which, when used properly, can become a tool for eliminating communication barriers with the aim of improving educational quality [25].

Specifically for students with hearing impairment, it is extremely important to use the visual channel, for which it is necessary to use technological tools that are presented visually, through images, and to adapt the vocabulary to facilitate understanding of the content [28].

The use of technology in the classroom provides students with the opportunity to access learning in an innovative way. In addition, it provides students with disabilities with a means of access to personal autonomy [29].

Taking into account all the circumstances mentioned above and wanting to focus on inclusive Physical Education for deaf students, the aim of this work is to show a didactic 
resource, easily exportable to other educational contexts, created to cover the needs of hearing-impaired students in relation to the possible practice of traditional games.

\section{Materials and Methods}

For the elaboration of this didactic proposal, we have relied on different resources that have made it very solvent at a scientific level.

On the one hand, a systematic bibliographic review was carried out to obtain quality scientific bibliography with which to approach our own work, and on the other hand, we had the opinion of experts who were interviewed so that they could give us feedback on the work proposed.

Subsequently, as will be explained below, the tools were developed, based on different electronic resources, which have given rise to our work proposal.

Each of these phases are explained below.

\subsection{Bibliographic Review}

The search has been carried out in the main sport databases SCOPUS based in Netherlands (Amsterdan), Google Schollar based in Mountain (US), and Isi Web of Knowledge based in Philadelphia (US), which we accessed from the subscription that the University of Seville has through the Spanish Foundation for Science and Technology (FECYT). The following keywords were entered in these databases: Information Technologies; IT; Sign Language; Hearing Impairment; Traditional Games; Primary School; Inclusive Education; Physical Education, crossing them with the Boolean operator "AND" and eliminating articles that were repeated. In the end, our selection of studies left only those directly related to the topic in question.

From this analysis, an extensive database of articles was obtained. Subsequently, through the bibliography of these articles, using the snowball methodology, other scientific articles and reference citations of interest were found, which provided additional highquality information for our proposal.

In this way, 130 quality documents were reviewed, totally or partially, of which 30 were directly used to carry out our study.

\subsection{Key Informant Interviews}

Due to the fact that this is an exploratory teaching proposal for a minority and vulnerable population, it was decided to opt for qualitative approaches to obtain the data we needed, specifically, we opted for the qualitative interview with semi-structured open-ended questions, for which four different interview scripts were developed. One for a Physical Education teacher with deaf pupils, one for the two interpreters, one for the Special Education teacher of deaf pupils and, finally, one for a deaf person. All these people were identified through a sampling of unusual cases [30] as do different studies with deaf population [31-37], following the recommendations of [38], the logic of the choice of the sample requires in some cases, as may be at risk or vulnerable populations, that these are selected intentionally, as is the case of the following study. Following the same logic and in order to be able to adequately reach the target population of deaf people, as well as to ensure that similar topics were addressed, the sampling used was also purposive [31], although participants were always allowed to participate in the study with their own ideas and opinions [39].

Once we had designed the didactic proposal for intervention in Physical Education through traditional games for people with and without hearing impairment, we asked key informants to give us their opinion on the work carried out, for which 5 people were interviewed.

An open-ended, semi-structured questionnaire was developed, consisting of 5 items relating to the clarity of explanations (signs used), image quality and contrasts, accessibility of information and usefulness of the tool. 
The first to be interviewed was a Primary School Physical Education teacher with hearing-impaired pupils in his classroom, who gave his own suggestions regarding how to explain to the pupils and what his main areas of need were when working with the group.

The second person was a teacher specialising in Special Education, who provided knowledge on the development of adapted tools for the target population.

The third and fourth people interviewed were sign interpreters from the Spanish Association of Deaf People who made suggestions on the appropriate signs to use for the didactic resources in order to ensure their correct interpretation by the disabled and non-disabled population.

Finally, also a deaf adult member of the international deaf association with high competences in the field of sports was interviewed and visualised the proposed tools and made her own contributions.

With the opinions of all informants and the own material elaborated from the previous literature search, as well as our own personal knowledge, we proceeded to the creation of the tools to be implemented in the classroom. We describe below the phases of their elaboration.

\subsection{Creative Process}

In order to develop the teaching resource, a series of steps were followed, which are described below.

Firstly, a new Google account was created in order to create and link a YouTube channel. Once the channel was created, the name was chosen, after thinking of several alternatives that were related to teaching and that were eye-catching, we decided to call it: "IDEAS DE MAESTRA" ("Teacher Ideas"), please see, Ideas de maestra-YouTube. Once we had the name chosen, we started with the artistic design of the channel, using for this the free graphic design tool "Crello". From which the following were created, the header was designed using a background provided by the online tool, through which the name chosen for the channel and its profile picture were added (Figure 3).

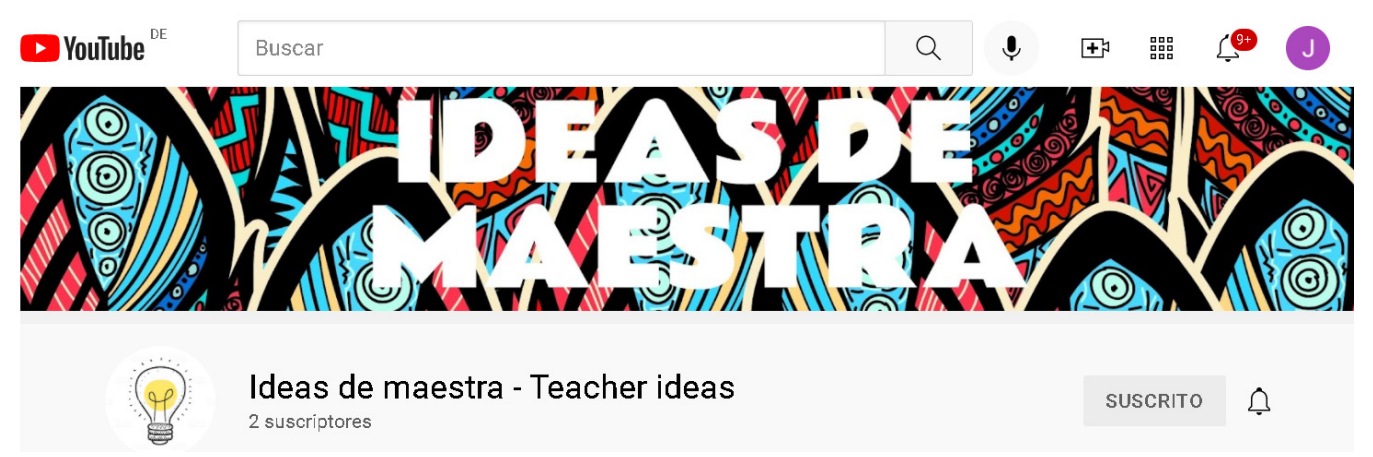

Figure 3. YouTube channel. Online: https://www.youtube.com/channel/UCjIa3159DhGOKu0 VRQRM5KQ/playlists/ (accessed on 11 November 2021).

Then, based on the six traditional games selected from the classification proposal of Ferrándiz \& Orden [25], a table was designed with the contents that were to be implemented and that could not be missing in each of them, so we can find: objectives, type of games, materials, description, graphic representation and QR code.

Then, we proceeded to work on the script of the text that the videos would contain and that would be translated into sign language, these would contain the descriptions of each traditional game, in order to make the tool accessible to students with hearing impairment and facilitate the work of communication between teacher-student in Physical Education classes.

The scripts of the videos were then translated, using international and Spanish sign language in first place, as well as others signs from the specific sports field that were adapted for this purpose, and and finally we also used other resources such as sign 
dictionaries, which included the Spread The Sign, and Sematosthat are reference tools in the world of hearing impairment.

Once the interpretations had been translated, the interpreter from the Spanish Sign Language Association was interviewed so that she could see the script and the chosen signs and give us feedback on any comprehension difficulties that might arise, as well as to practice the fluency of the interpretations with her prior to the video. Then, to make sure that the interpretations were clear and understood, the videos were recorded and sent to a double-blind, i.e., another sign language interpreter for her professional opinion.

Each of the videos was double-checked by professional sign language interpreters until the final recording of the videos could be made. The drafts of the videos were recorded with the mobile phone, and edited with the computer application Movie Maker, since, for each game, at least six recordings had to be made, which were then edited to create a single video for each game designed (Figure 4).

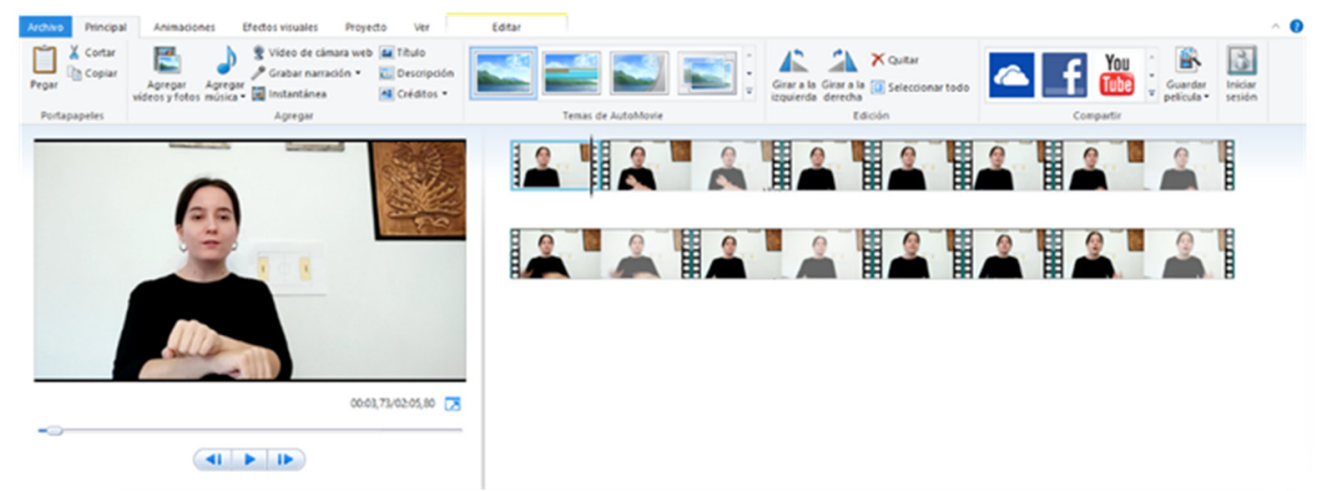

Figure 4. Editing of the first video version with Movie Maker. Draft. Online: https:/ /www.youtube. com/channel/UCjIa3159DhGOKu0VRQRM5KQ/playlists/ (accessed on 11 November 2021).

After all this preliminary work, the final recordings were made. For the development of the videos and with the objective of having a high-quality result, a final version was made using a high-quality Canon camera.

Every detail of the recording was previously thought out, such as the background with the white board, with the aim of highlighting the figure of the interpreter, who is dressed in black (high visual contrast), and to provide visual support in the explanation of the games. In the final version of each game, several video cuts were made, which on this occasion were joined together using the Filmora programme to obtain the expected result. In addition, to make it more entertaining and dynamic for the pupils, the signed videos were interspersed with the explanations and demonstration videos, so that the pupils could see what the game is really like.

In order for the content of the tool to be useful for both hearing and deaf pupils and teachers, it was considered necessary to subtitle them.

In order to break the possible monotony, it was decided to divide the video in two: in the first part, we can see a brief explanation and, in the second part, the rules of each game. Finally, it should be noted that the videos have no sound in order to facilitate their use in class without disturbing the rest of the classmates (Figure 5).

Once all the videos had been edited and saved, they were uploaded to the YouTube channel created earlier. The way to publish the videos on the channel has been hidden, so that only people who have the URL can see the content of the videos.

To generate the QR codes, we used the online tool QRCode Monkey, where we only had to paste the URLs of the videos, add the name, description and shape of the codes.

For each video, a different code has been designed with different colours. In addition, the YouTube logo can be found in the centre.

The result of all this work described in the methodology can be found on the following YouTube channel, https: / /www.youtube.com/channel/UCjIa3159DhGOKu0VRQRM5KQ/ 
playlists (accessed on 11 November 2021), "Ideas de Maestra" in the section of the channel called "list". You can also access it by scanning the following code (Figure 6).

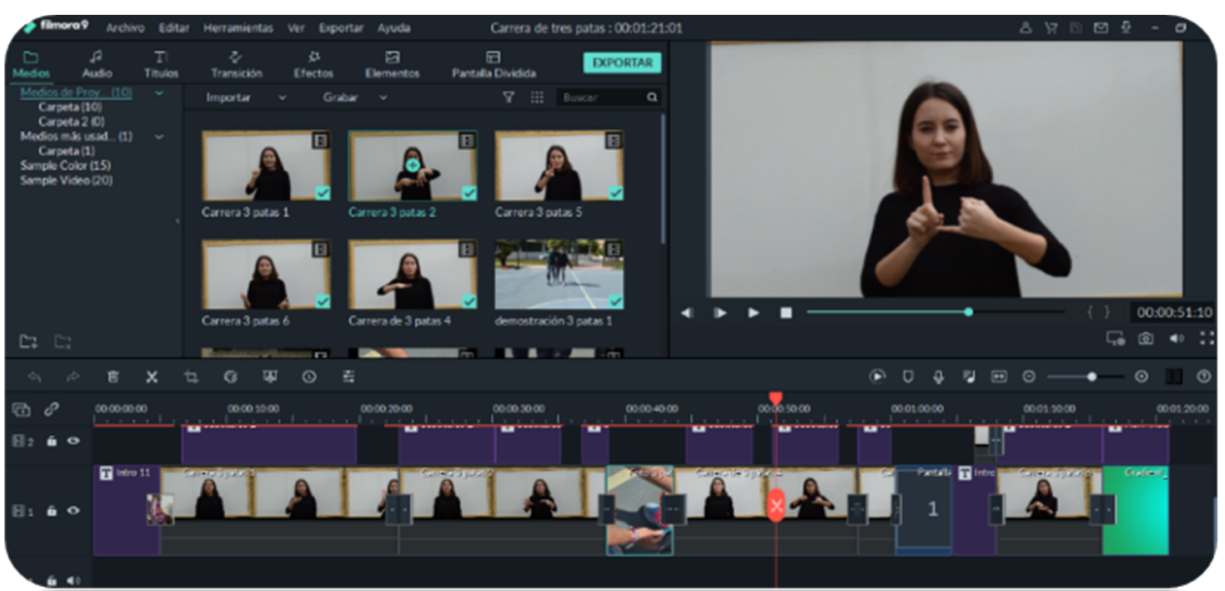

Figure 5. Editing the second version of the video with Filmora. Definitive. Online: https: / / www.youtube.com/channel/UCjIa3159DhGOKu0VRQRM5KQ/playlists / (accessed on 11 November 2021).

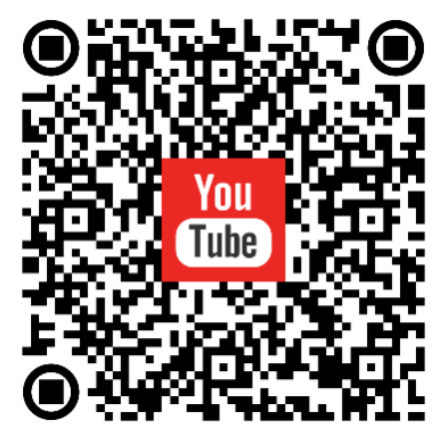

Figure 6. QR code for access to the Sign Language YouTube channel. Online: https:/ / www.youtube. com/channel/UCjIa3159DhGOKu0VRQRM5KQ/playlists/ (accessed on 11 November 2021).

\section{Results}

At present, the most common recommendations and aids for deaf people in Physical Education classes are basically of three types [40]:

1. Physical or spatial adaptations (good visibility of the teacher's face);

2. Communicative adaptations (using a natural and normal tone of voice, without shouting, explaining visually any rule or norm, using signs and signals);

3. Adaptation of materials and technical aids (use of visual aids such as blackboards or technological elements, the figure of the collaborating pupil).

In our case, we have decided to focus on inclusion strategies related to the third type mentioned above, specifically with the use of technical aids that help the student to carry out the designated game without significant adaptations and without the help of a collaborating student who relays the teacher's message in an adapted way, specifically through the use of mobile devices with internet connection and QR code readers; although, it is true that these adaptations are not worked on in a unitary way, but are supported by and include other types of those previously mentioned, such as the use of signs and signs, according to other authors [41].

In this way, we now proceed to explain the development of our creative proposal in the different phases of its process.

A dossier of traditional games has been designed according to the disposition of the pupils and the objective set. The games will be arranged in a table with the objectives, 
materials, description, adaptations and their corresponding QR codes. Each game will be structured according to the following model (Table 1):

Table 1. Game description.

\begin{tabular}{ccc}
\hline & Game Name & \\
\hline Objective & Distribution & Materials \\
\hline & Description & \\
\hline Graphic Description & Qr Code & \\
\hline
\end{tabular}

Each board, depending on the arrangement of the students, will be in a different colour, being blue for individual games, yellow for individual opposition, green for cooperation and purple for cooperation-opposition. This grouping will be specified in the layout section. In addition, there will be specific objectives for each traditional game. In the square of materials, the necessary materials for each game will be listed. A brief description is set out clearly and concisely, as well as being accompanied by its own graphic description, in order to support the explanation. Finally, the QR codes of the descriptions of the games are adapted to Spanish sign language.

The purpose of this dossier of traditional games is to facilitate communication and inclusion of students with hearing impairment in Physical Education classes for teachers, that is, to create a didactic resource to develop traditional games, eliminating the possible communication barriers present in the classroom.

The games we have chosen represent all the categories of the classification [25] of the games according to the participation and communication that we have proposed in our didactic proposal, in this way, we have chosen: 1 . Individual games, specifically the "hopscotch", 2. Opposition games such as the "Sack Race", 3. Cooperative games such as "The Wild Wheelbarrow Race" or the "Three-legged race" and, finally, 4. Cooperation/Opposition games such as the "Steal the Bacon Game" or the "Dodgeball Game". These traditional children's games are widespread globally, having been detected in most of Europe and North America.

In addition, a glossary has been designed to collect the words related to each traditional game and the most technical words used when explaining them. A QR code has also been created for the alphabet.

\subsection{Dossier of Traditional Games}

The main contribution of this work can be seen below, we refer to the dossier of traditional games prepared with their corresponding video linked by $\mathrm{QR}$ code, which when scanned leads to the video inserted in a YouTube channel, all the games have been adapted according to the recommendations set out above and the visual support of the attached video finishes making this activity totally inclusive.

However, we would like to make some clarifications in relation to the target age group for a better understanding of the didactic proposal.

First of all, the proposal has been adapted to the Spanish educational context, without detriment to the fact that this work can be replicated in other contexts, in this national reality, the basic motor skills are worked on, as also proposed by García et al. [42] from 7-9 years of age, which corresponds to the second cycle or 3rd and 4th grades of primary school, and this is the level for which the entire proposal has been prepared, although we consider that this resource can be used in later grades, increasing the complexity of the execution of the tasks.

These traditional games are immersed and regulated in the curriculum of the subject of Physical Education at national level in Spain, in a concrete way by the Spanish Royal Decree $126 / 2014$, of 28 February, which establishes the basic curriculum of Primary Education in Spain, and which organizes it in 5 blocks: 1 . The body, image and perception, 2. Motor 
skills, 3. Artistic and expressive physical activities, 4 . Physical activity and health, and 5. Games and sports activities.

These games that we developed are included in the contents 2 relating to Motor Skills, and and 5 relating to Games and sports activities.

\subsubsection{Individual Games}

The first game is called "hopscotch" and its main objective is to improve precision throwing and coordination, as well as to develop jumping and static and dynamic balance, which is often lacking, in part, in the deaf population. Please see the description sheet (Figure 7).

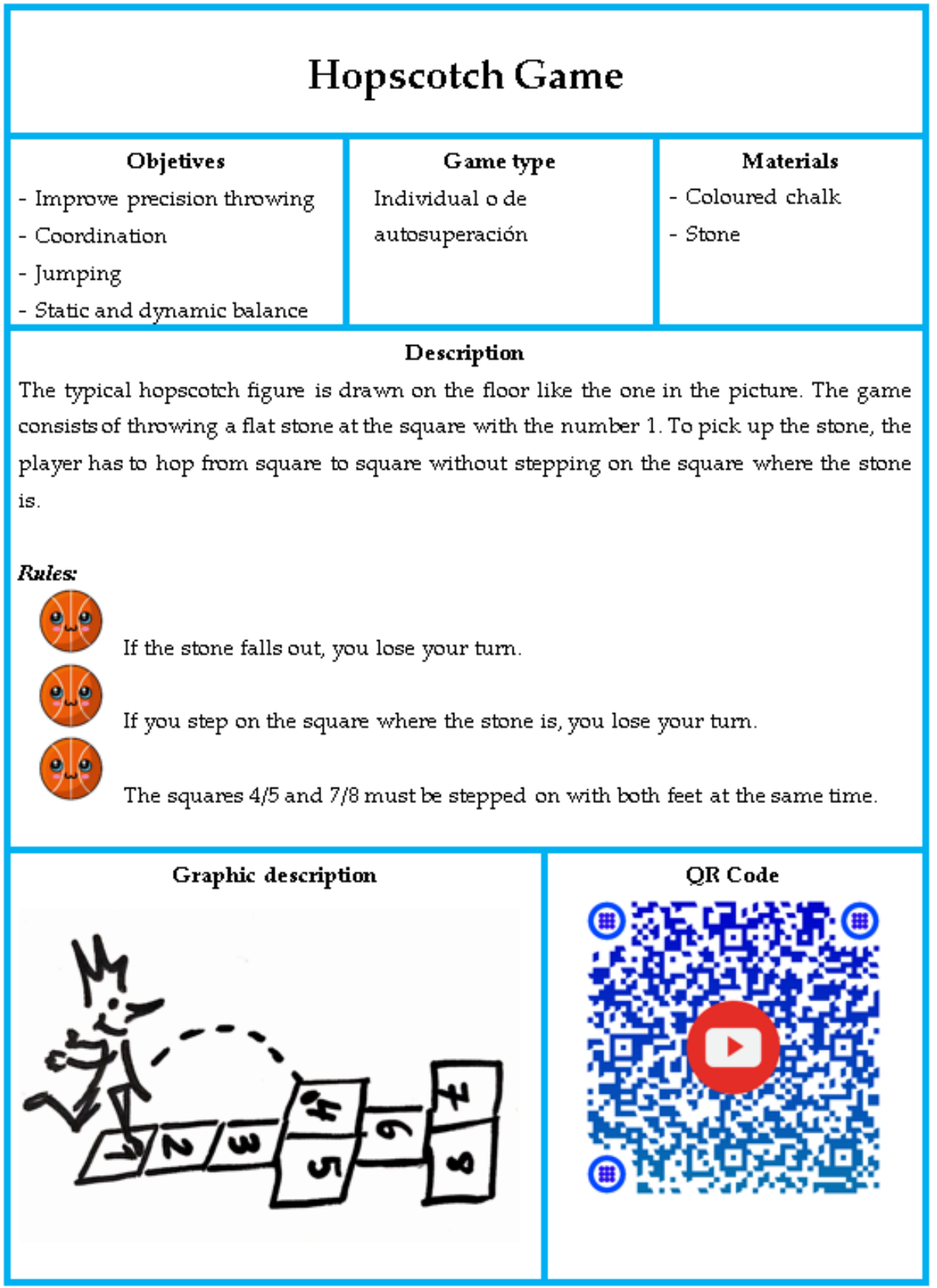

Figure 7. Hopscotch.

Hopscotch is a traditional game played in many European and Latin American countries that consists of throwing a small object into squares or triangles marked on the ground, and then moving over them by jumping with one or both legs until the object is reached. 


\subsubsection{Games with Opposition}

The second game is called "Sack Race" and its main objective is to develop dynamic balance on both feet, as well as dynamic hand-eye coordination and strength, mainly through jumping power. Please see the description sheet (Figure 8).

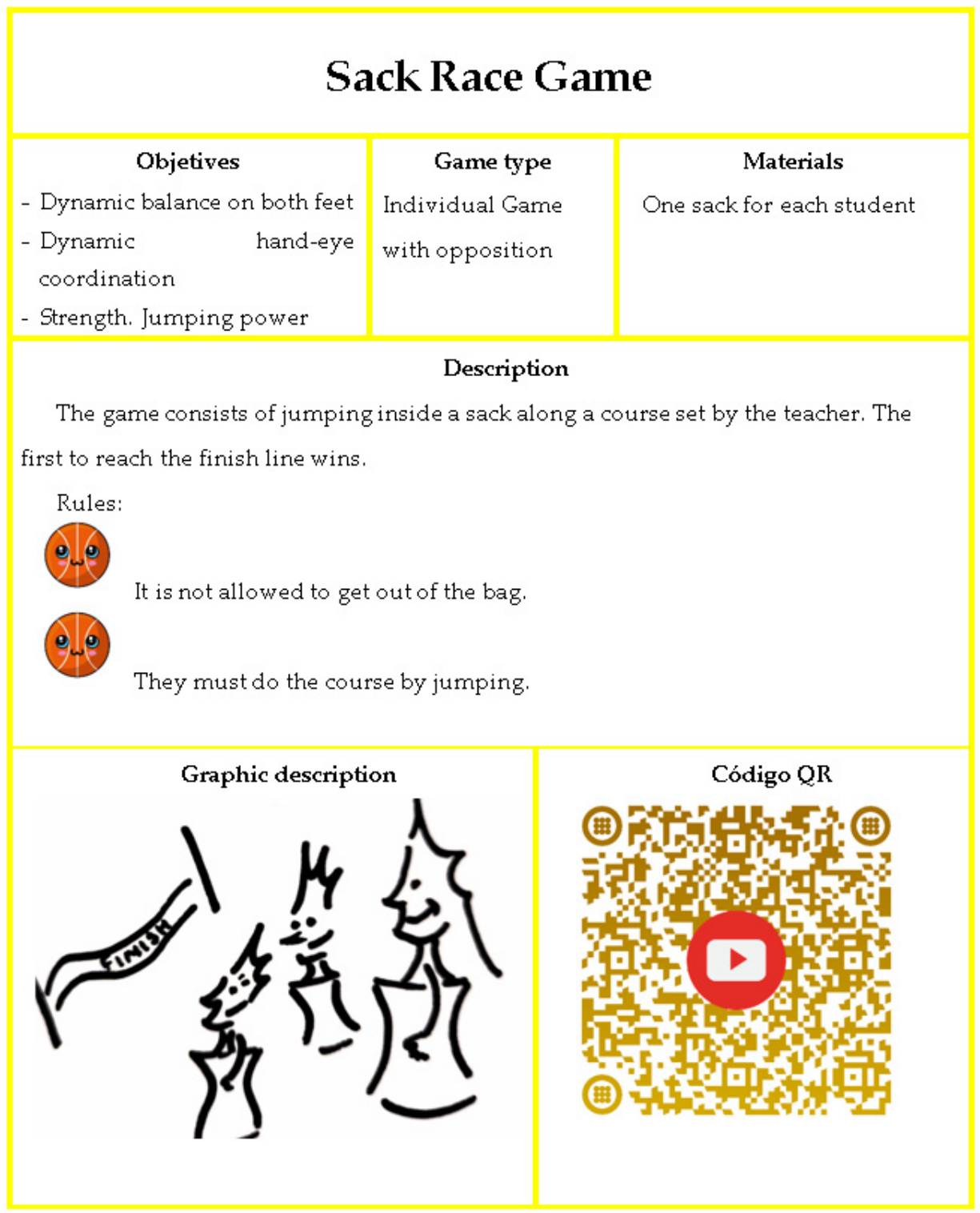

Figure 8. Sack Race.

The sack race is a well-known game played almost all over the world. With this individual game, the aim is to run the fastest race with both feet in a sturdy bag or sack, the best way to do this is to jump with your feet together while grabbing the sack with one or both hands. Often the physically strongest person is not the one who wins the race but the one who sets the best strategy and has the best coordination.

\subsubsection{Cooperative Games}

The third game is called "The Wild Wheelbarrow Race" and its main objective is to promote cooperative work in pairs, communication between equals, and the development of strength. Please see the description sheet (Figure 9). 


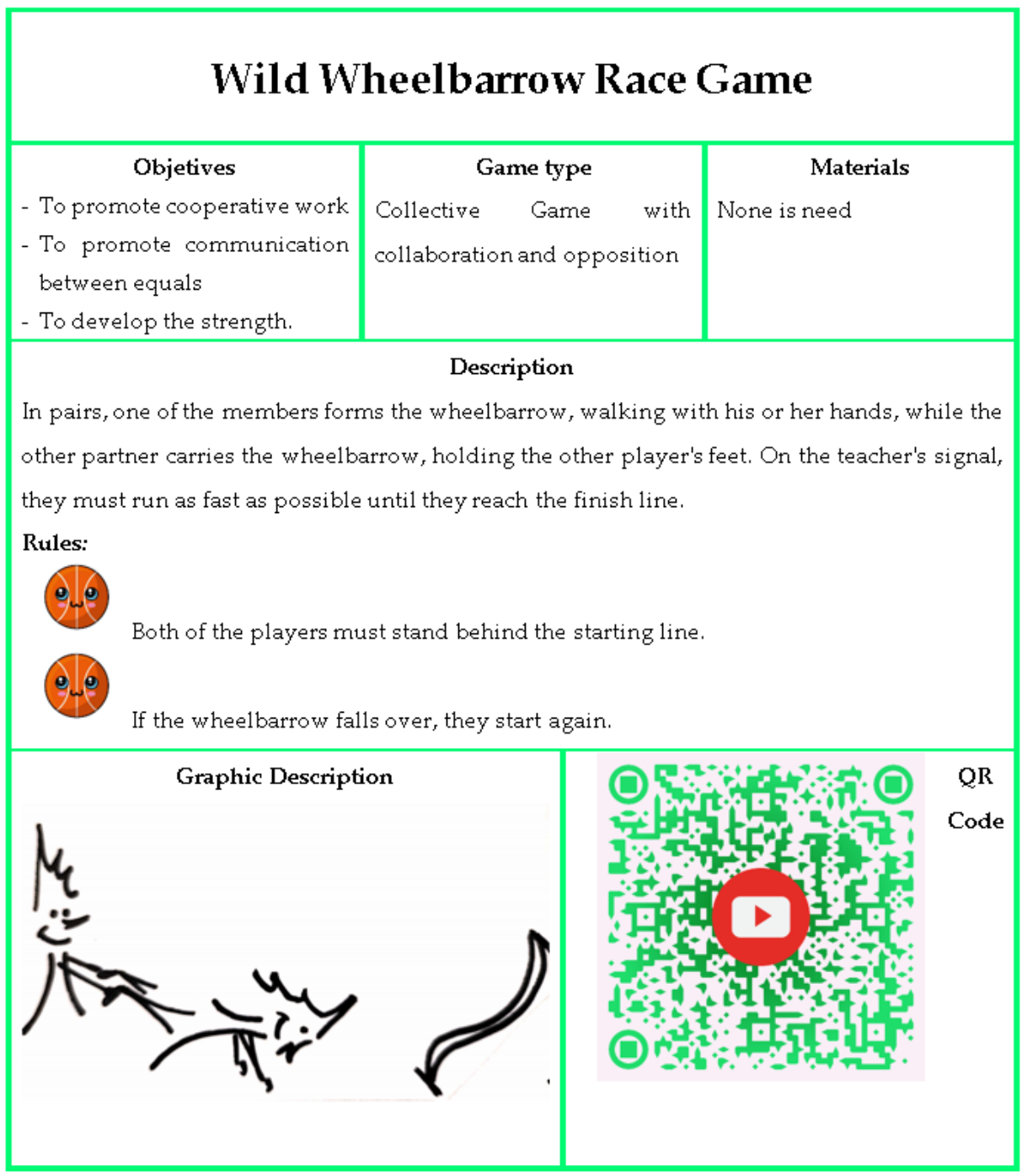

Figure 9. Wild Wheelbarrow Race.

"The Wild Wheelbarrow Race" is a funny type of race where one of the pair extends the arms and hands on the floor, and the legs remain extend, while the second of the two holds the first one from the ankles. From this position, they have to move as quickly as possible between two marked spaces.

The fourth cooperative game is called "Three-legged race" and its aim, as in the previous game, is to encourage cooperative work in pairs, communication between peers and above all to have fun. Please see the description sheet (Figure 10).

The three-legged race game is a game in which you run between two marked points in space in cooperation with a partner to whom you are tied by means of a rope at ankle level.

\subsubsection{Cooperative and Opposition Games}

The fifth game is called "Steal the Bacon Game" and its aim is to encourage cooperative collective work in a team but playing against another (opposition), being attentive to the signals given by the referee is fundamental, as well as being able to make spontaneous decisions when it comes to taking the object and running away from the opponent or vice versa. This is a game full of nuances with a great strategic component. Please see the description sheet (Figure 11). 


\section{Three-legged Race Game}

\begin{tabular}{l|l|l}
\multicolumn{2}{c|}{ Objetives } & \multicolumn{2}{c}{$\begin{array}{c}\text { Mame typerials } \\
\text { - To promote cooperative work } \\
\text { - To promote communication } \\
\text { between equals }\end{array}$} & $\begin{array}{l}\text { Individual Game with A rope to tie the } \\
\text { collaboration and opposition }\end{array}$ & legs \\
\hline \multicolumn{3}{c}{ Description }
\end{tabular}

In pairs, tie each other up with a rope at ankle level. The right leg of one partner and the left leg of the other partner remain free. When they are all tied together, they stand behind the starting line. The game consists of running to the finish line.

Rules:

They must have their legs tied together.

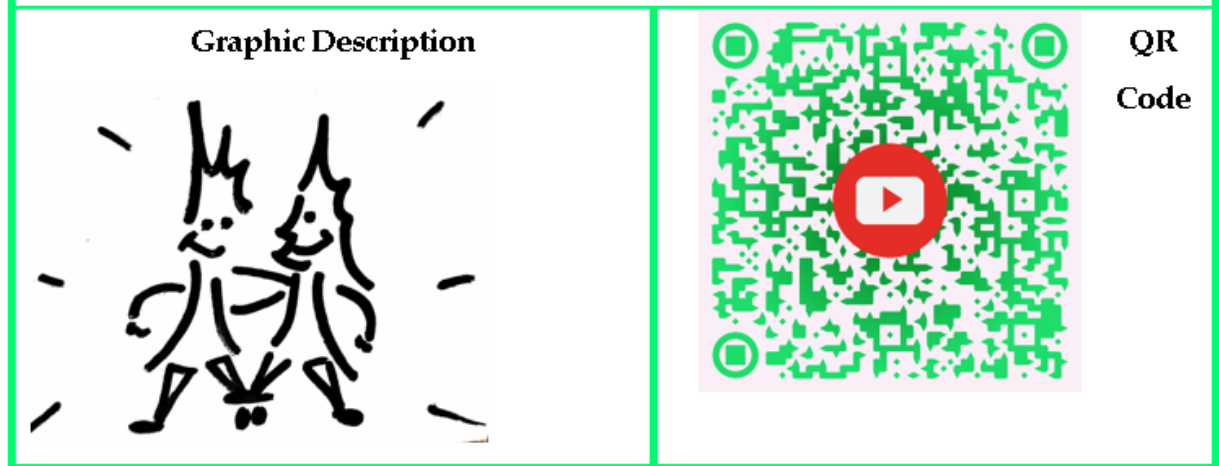

Figure 10. Three-legged Race.

In the game "Steal the Bacon", a series of numbers are secretly assigned to all members of a team who compete with the same numbers against the members of the other team. As soon as the referee calls out a random number, one member of each group races out to try to catch the object held by the referee and avoid being caught by the teammate who arrives later, or vice versa.

The sixth game is called the "Dodgeball Game" and its aim is to encourage cooperative collective work in a team but playing against another (opposition). In this game, it is essential to have fluid communication with teammates and to establish a collective team strategy, being able to sacrifice oneself for the group in order to win the game, which makes this game especially interesting because it even encourages solidarity. Please see the description sheet (Figure 12).

In the Dodgeball Game, the players are set up in two separate fields, which in turn, at the back, has another field reserved for the players of the opposing team. The aim of this game is to eliminate the teammates of the opposing team by hitting any part of their body with the ball, without penetrating their field, and no letting them reaching the ball once they have been hit.

Finally, we would like to show a glossary of concepts that will be taught to the class for a better understanding of the sessions, please see below (Table 2). 


\section{Steal the Bacon Game}

\begin{tabular}{l} 
Objectives \\
$\begin{array}{l}\text { - To develop reaction speed and running } \\
\text { Collective Game with } \\
\text { skills. }\end{array}$ An object that acts as \\
- To keep the pupils' attention. \\
- Promotes the capacity for improvisation. \\
- Promotes the ability to make decisions in a \\
consensual manner. \\
\hline
\end{tabular}

The class is divided into two groups with the same number of pupils and arranged in two rows facing each other at a distance of approximately 10-15 metres. Each member of the group is assigned a number without repetition. In the middle of the two teams, a person is placed in charge of holding the bacon and calling out the numbers. When the number is called out, one pupil from each team runs to the centre and has to catch the handkerchief without the opponent catching it. The team with the most points wins.

Rules:

If the teammate is caught by the opponent who has taken the handkerchief, he/she wins the point.

If the student who has taken the handkerchief manages to reach his zone without being caught by the opponent, he wins the point.

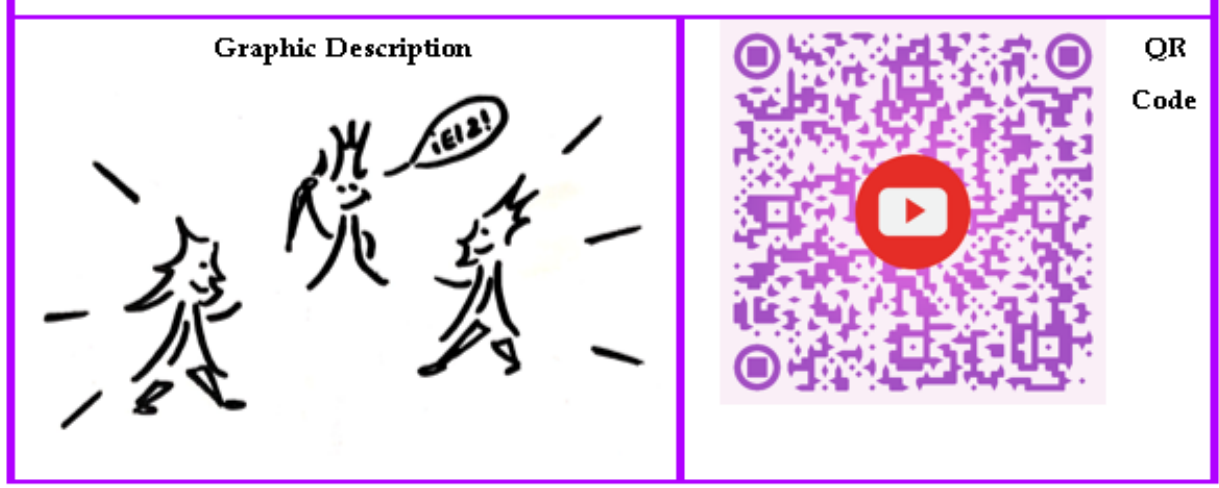

Figure 11. Steal the Bacon Game.

Table 2. Glossary of concepts.

\begin{tabular}{|c|c|c|c|}
\hline & Words & & QR Code Annexed \\
\hline Ball & Start & Play & (뾰 \\
\hline Running & Team & Launch & \\
\hline Partner & Win & Goal & \\
\hline Area/zone & Loose & Rules & 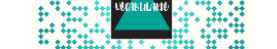 \\
\hline Pair & Playground & Prepare & 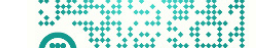 \\
\hline Quick & Exit & Turn & (19) \\
\hline
\end{tabular}




\section{The Dodgeball Game}

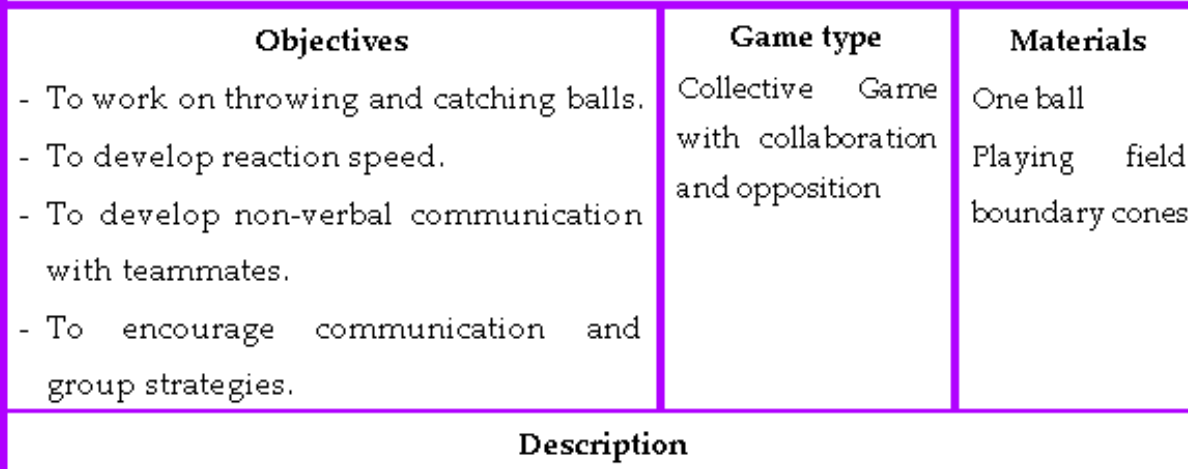

The class is divided into two groups with the same number of participants and each team is arranged on one side of the court. The game consists of throwing a ball and hitting an opponent. The tea m with the most members on their side wins.

\section{(1) Rules:}

If you hit a teammate when throwing the ball, he/she goes to the end of the opponent's court (jail).

(6) If the opponent catches the ball without it having fallen to the ground beforehand, the student who threw the ball moves to the end of the opponent's court (jail).

To save himself, his tea mmates must pass him the ball and he must throw it to try to hit an opponent.

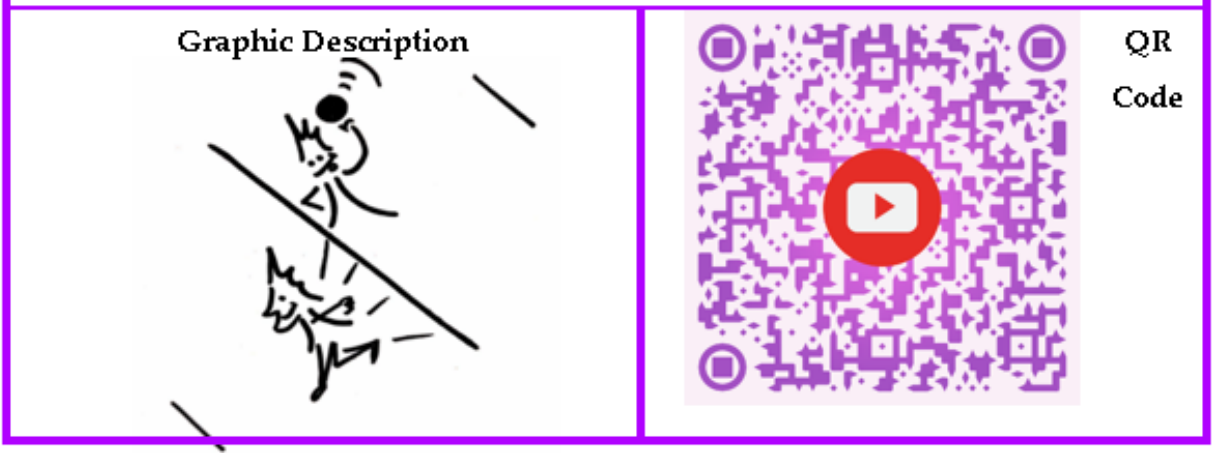

Figure 12. The Dodgeball Game.

\section{Conclusions}

Play in childhood is fundamental for the correct psychological and psychomotor development of children [43], as it favours a correct evolution in all areas of their development, especially in the field of socialisation with their peers.

In this didactic proposal, we have opted to focus on traditional games, which according to Lavega [21], through them we get to know the customs and traditions of childhood, which in many cases, as in those shown in this proposal, are played almost all over Europe and America. This produces a democratization of universal motor performance, as many children in many countries could play the same games with the same rules, overcoming possible language or cultural barriers. This again has a positive impact on the integration of deaf people, who are recognised as a cultural and linguistic minority that can be included based on common languages, even universal languages of communication, such as games [16]. 
Although this is a proposal model that has not been put into practice, we consider it to be well-founded, since in addition to an extensive bibliographical review, we have had the opinion of experts who have given their opinion on the aspects to be implemented in the tool created.

The integration of students with disabilities in physical education usually requires a reflection and analysis of the real needs of each specific situation without necessarily hiding behind a lack of material or personnel [44], the material created provides an approach of applicability in a preview format for a simultaneous inclusion.

In this way, a Special Education teacher, a Physical Education teacher and a sign language interpreter have been contacted and their opinions have been taken into account as follows [45].

With regard to the opinion of a Special Education teacher, it can be highlighted that she found it a suitable tool to put it into practice in the classroom, since, as it is explained with demonstrations, subtitled and with slow sign language, it is possible to attribute meanings to different signs, which normalises the situation without establishing differences between pupils. In addition, it arouses the curiosity of the rest of the classmates to learn this language.

Physical education teachers need resources for intervention as Ochoa-Martinez [45] points out, indicating that they are not prepared to be able to teach hearing impaired students, and for this, they need interactive and motivating resources such as Apps and video tutorials similar to those proposed.

The Physical Education teacher, for his part, and according to his experience, expresses a similar opinion to that of the previous teacher and highlights the importance of rescuing traditional games, which in some cases are being lost.

As for the interpreter's opinion, she thought it was an appropriate tool because it encourages the independence of the pupils in the PE class and increases accessibility for deaf pupils. In addition, the interpreter is usually hired part-time, so it is precisely in PE, music or art classes where they are not usually present, which makes access to information difficult, so the possibility of having this tool facilitates the inclusion of pupils.

This proposal enriches all stimulation that can be offered to hearing impaired pupils [45]. Early intervention programmes during the primary education stage, with communication adapted to the needs of each student, ensure that their motor development is in accordance with their biological age and is not diminished by a lack of activities or information resources [40].

It is common in our daily life that when we have doubts about a subject, we consult it on a network such as YouTube and there is none of this type adapted to deaf people. In this way, by enabling this resource, we improve accessibility to information for sign language users.

Sign language is not only a tool that eliminates possible communication barriers, but it is the natural language with which many people communicate and, therefore, every teacher should know it, because as we have mentioned above, introducing this language in classrooms where there are people who need it, will favour their complete and correct cognitive and social development. In addition, to be able to awaken in the rest of the students and teaching staff the desire to learn it, to sow from the base, that is, the students, a change in order to develop a more equitable society, as Mahatma Gandhi said: "be the change you want to see in your life".

We understand as very important the use of an ICT tool for the inclusion of the deaf collective in the Physical Education classroom, we have achieved this from the development of $\mathrm{QR}$ codes that can be viewed through mobile devices available in schools such as tablets; these codes link them to a YouTube link where they can view a video in sign language that will facilitate the understanding of the exercise proposed by the teacher.

We consider ICT to be a resource accessible to all; intuitive for the new generations and above all easy to use, which, if used well, can be used for the inclusion of this group. 
These tools, combined with games, provide multiple benefits, as [44] pointed out, as well as boosting and stimulating learning and relationships between peers.

The proposal is in line with the parameters and needs indicated by other studies for the improvement of development and optimisation of learning in hearing-impaired students $[45,46]$. However, it must be said that the proposal has not been carried out and implementation would be a determining factor to know its effectiveness.

In this work, we have tried to follow all the recommendations on the design of videos for deaf people as suggested by [47], such as facial expressions, head movement, or different body movements, as well as capturing half of the body with more movement from the trunk, through the arms and head, and we have used black monochrome uniform clothing that makes it easier to pay attention to the interpreter's signs. We have also ruled out the inclusion of avatars or sign language translation programmes, such as ProDeaf and Google Gesture HandTalk, which, although they may be more or less useful, leave out the subtlety of the real human gesture, which is often decisive for understanding a message, so we have opted to incorporate a real model with advanced knowledge of sign language and communication in the recording of the videos.

We consider that the application of this work can be positive, as long as the basic considerations in communication with deaf people are taken into account [48,49], being the proposed work a technological implementation that improves communication and independence of the student but assuming and taking into account the aspects of basic communication with these people in fact as pointed out by [50]; the visualisation of a signed video is not sufficient communication to understand the requested activity and secondly, the lack of knowledge of the technological elements, often aggravated in the deaf population [47], which presents greater deficiencies than the hearing population. For all the above-mentioned, we must be aware that, finally, the technological proposal presented to support an improvement in the autonomy of deaf people in the Physical Education class, is not a substitute for the figure of the teacher who must always be present to support his students when they require it.

Author Contributions: Conceptualization, J.F.-G. and D.M.-S.; methodology, V.A.-R.; software, P.E.-G.; formal analysis, P.E.-G.; investigation, J.F.-G. and P.E.-G.; resources, V.A.-R.; data curation, D.M.-S.; writing—original draft preparation, J.F.-G. and P.E.-G.; writing—review and editing, D.M.-S., V.A.-R.; visualization, J.F.-G.; supervision, D.M.-S.; project administration, J.F.-G.; funding acquisition, J.F.-G., D.M.-S., V.A.-R. and P.E.-G. All authors have read and agreed to the published version of the manuscript.

Funding: This research has been funded partially by the Valencian International University.

Institutional Review Board Statement: Not applicable.

Informed Consent Statement: As it is a didactic proposal that has not been put into practice, no subject's consent has been required.

Data Availability Statement: The material can be found hosted online: https:/ / www.youtube.com/ channel/UCjIa3159DhGOKu0VRQRM5KQ/playlists / (accessed on 11 November 2021).

Acknowledgments: We would like to express our gratitude to the collaborators of the Spanish Association of the Deaf as well as to all those experts who have participated in the revision of the didactic proposal presented here.

Conflicts of Interest: The authors declare no conflict of interest.

\section{References}

1. Bravo, J. Deafness in Figures. Available online: http://blog.beltone.es/la-sordera-cifras/ (accessed on 23 October 2021).

2. García-Perales, F..; Herrero-Priego, J. Manual de Atención al Alumnado con Necesidades Específicas de Apoyo Educativo Derivadas de Discapacidad Auditiva; Consejería de Educación: Sevilla, Spain, 2008.

3. INE. Survey on Disability, Personal Autonomy and Situations of Dependence. Available online: https://www.ine.es/dyngs / INEbase/es/operacion.htm?c=Estadistica_C\&cid=1254736176782\&menu=resultados\&idp=1254735573175\# (accessed on 8 November 2021). 
4. Strong, M.; Priz, P.M. A Study of the Relationship Between American Sign Language and English Literacy. J. Deaf. Stud. Deaf. Educ. 1997, 2, 37-46. [CrossRef] [PubMed]

5. Cawthorn, S. Teaching strategies in inclusive classrooms with deaf students. J. Deaf. Stud. Deaf. Educ. 2001, 6, 212-225. [CrossRef] [PubMed]

6. Marschark, M.; Young, A.; Lukomski, J. Perspectives on inclusion. J. Deaf. Stud. Deaf. Educ. 2002, 7, 187-188. [CrossRef] [PubMed]

7. Stinton, M.S.; Antia, S.D. Considerations in educating deaf and hard-of-hearing students in inclusive settings. J. Deaf. Stud. Deaf. Educ. 1999, 4, 163-175. [CrossRef]

8. Foster, S.; Mudgett-Decaro, P.; Bagga-Gupta, S.; De Leuw, L.; Domfors, A.; Emerton, G.; Lampropoulou, V.; Ouellette, S.; Van Weert, J.; Welch, O. Cross-Cultural definitions of inclusion for deaf students: A comparative analysis. Deaf. Educ. Int. 2003, 5, 1-19. [CrossRef]

9. Hintermair, M. Health-related quality of life and classroom participation of deaf and hard-of-hearing students in general schools. J. Deaf. Stud. Deaf. Educ. 2011, 16, 254-271. [CrossRef]

10. Borders, C.M.; Herman, M.; Giese, K.; Tess, A. Special education for young learners who are deaf/hard of hearing. Adv. Spec. Educ. 2019, 34, 73-86. [CrossRef]

11. Hall, W.C. What You Don't Know Can Hurt You: The Risk of Language Deprivation by Impairing Sign Language Development in Deaf Children. Matern. Child Health J. 2017, 21, 961-965. [CrossRef]

12. Murray, J.J.; Hall, W.C.; Snoddon, K. Education and health of children with hearing loss: The necessity of signed languages. Bull. World Health Organ. 2019, 97, 711-716. [CrossRef]

13. Herrera, V. Adquisición temprana de lenguaje de signos y dactilología. Rev. Psicopedag. 2005, 13, 2-10.

14. Esteban-Saiz, M.L.; Aroca-Fernández, E.; Rodríguez-Varela, M.; Sánchez-Moreno, D. ¿Las lenguas de signos siguen siendo lenguas minorizadas? Política y planificación lingüísticas. In Proceedings of the Congreso Internacional de Lingüística Xeral Vigo, España, 13-15 June 2018; Díaz, M., Vaamonde, G., Varela, A., Cabeza, M.C., García-Miguel, J.M., Ramallo, F., Eds.; CILX: Vigo, Spain, 2018; pp. 328-335.

15. Marschark, M.; Zettler, I.; Dammeyer, J. Social dominance orientation, language orientation, and deaf identity. J. Deaf. Stud. Deaf. Educ. 2017, 22, 269-277. [CrossRef] [PubMed]

16. Huerta, C.; Varela, J.; Soltero, R.; Nava, G. No a la discapacidad: La Sordera como minoría lingüística y cultural. Rev. Nac. Int. Educ. Inclusiva 2018, 11, 63-80.

17. Chapman, M.; Dammeyer, J. The significance of deaf identity for psychological well-being. J. Deaf. Stud. Deaf. Educ. 2017, 22, 187-194. [CrossRef] [PubMed]

18. CEJA. Orden de 17 de Marzo de 2015 Por la Que se Desarrolla el Currículo Correspondiente a la Educación Primaria en Andalucía. Available online: http://www.juntadeandalucia.es/educacion/descargasrecursos/curriculo-primaria/pdf/PDF/textocompleto. pdf (accessed on 23 October 2021).

19. Miraflores, E.; Ibáñez, N. Juegos Populares y Tradicionales Para Educacióninfantil; CCS: Madrid, Spain, 2015.

20. Gallardo, P.; Fernández-Gavira, J. El Juego Como Recurso Didáctico en Educación Física; Wanceulen: Sevilla, Spain, 2010.

21. Lavega, P. Juegos y Deportes Tradicionales; Inde: Barcelona, Spain, 2000.

22. Cruz, L.M.S. La enseñanza de los juegos tradicionales: ¿Una posibilidad entre la realidad y la fantasía? Educ. Física Deporte 2008, $27,115-122$.

23. Lavega, P. El juego y la tradición en la educación de valores. Educ. Soc. Rev. Interv. Socioeducativa 2006, $33,54-72$.

24. Lavega, P.; Olaso, S. 1.000 Juegos y Deportes Populares y Tradicionales; Paidotribo: Badalona, Spain, 2007.

25. Ferrándiz, I.M.; Orden, V.J. Educación Física Para el Tratamiento de la Diversidad; UNED-Universidad Nacional de Educación a Distancia: Madrid, Spain, 2011.

26. Hernández, R.M. Impacto de las TIC en la educación: Retos y Perspectivas. Propósitos Represent. 2017, 5, 325-347. [CrossRef]

27. Salazar, D. Las TIC Como Desarrollo Personal y Social. In Revista de Investigaciones de la Escuela de Ciencias Sociales; National Open and Distance University (UNAD): Bogotá, Colombia, 2015; Volume 6, pp. 151-153.

28. Rodríguez, M.; Arroyo, M.J. Las TIC al servicio de la inclusión educativa. Digit. Educ. Rev. 2014, 25, $108-126$.

29. Cacheiro, M. Educación y Tecnología: Estrategias Didácticas Para la Integración de las TIC; UNED: Madrid, Spain, 2014.

30. López, P.L. Población muestra y muestreo. Punto Cero 2004, 9, 69-74.

31. Kritzinger, J.; Schneider, M.; Swartz, L.; Braathen, S.H. "I just answer 'yes' to everything they say": Access to health care for deaf people in Worcester, South Africa and the politics of exclusion. Patient Educ. Couns. 2014, 94, 379-383. [CrossRef]

32. Mulonda, M. A Situational Analysis on the Use of Sign Language in the Education of the Deaf in Zambia: A Case of Magwero and ST. Joseph Schools for the Deaf. Ph.D. Thesis, University of Zambia, Zambia, East Africa, 2013.

33. Mulyadi, E.; Oktavianisya, N.; Puspaningrum, U. Communication and Self-Concept of Children with Deaf and Speech Impaired. J. Vocat. Nurs. 2020, 1, 105-110. [CrossRef]

34. Yadavalli, P.K. The Educational Practices for Teaching Students with Hearing Impairment in Case of Ambo Lazarist Catholic School for the Deaf in Ambo Town, Ethiopia. Educ. Plus 2018, 1, 1-9.

35. Alanazi, M. Communicating with Deaf Students in Inclusive Schools: Insights from Saudi University Faculty. Eurasian J. Educ. Res. 2021, 95, 188-209. [CrossRef]

36. Gharashi, K.; Moheb, N.; Abdi, R. Effects of acceptance and commitment therapy on decreasing anxiety and depression symptoms in mothers of hearing-impaired or deaf children. Audit. Vestib. Res. 2019, 28, 116-123. [CrossRef] 
37. Teklemariam, A. Impacts of Congenital Deafness on Language and Cognitive Development of Primary Schools Deaf Students in Addis Ababa. East. Afr. Soc. Sci. Res. Rev. 2019, 35, 4-28. [CrossRef]

38. Pineda, B.; De Alvarado, E.; De Canales, F. Metodología de la Investigación, Manual Para el Desarrollo de Person al de Salud; Organización Panamericana de la Salud: Washington, DC, USA, 1994.

39. Bless, C.; Higson-Smith, C. Fundamentals of Social Research Methods-An African Perspective; Creda Communications: Cape Town, South Africa, 2000.

40. Soto-Rey, J.; Pérez-Tejero, J. Experiencia práctica: Estrategias para la inclusión de personas con discapacidad auditiva en educación física. Rev. Española Educ. Física Deportes 2014, 406, 93-101.

41. Lucas, M.D. Procedures for working with students with deafness or hearing impairments in general physical education. VAHPERD J. 2009, 30, 23-26.

42. García, E.F.; Torralba, M.L.G.; Bañuelos, F.S. Evaluación de Las Habilidades Motrices Básicas; Inde: Barcelona, Spain, 2007.

43. MacNamara, Á.; Collins, D.; Giblin, S. Just let them play? Deliberate preparation as the most appropriate foundation for lifelong physical activity. Front. Psychol. 2015, 6, 15-48. [CrossRef] [PubMed]

44. Bonany, T.; Carol, N.; Blanco, A.; Ríos, M. Actividad Física Adaptada: El Juego y Los Alumnos Con Discapacidad; Paidotribo: Badalona, Spain, 2016.

45. Ochoa-Martínez, P.Y. Experiencia didáctica en educación física para la mejora de actitudes hacia la discapacidad auditiva en futuros profesionales de la actividad física y deporte. Retos Nuevas Tend. Educ. Física Deporte Recreación 2021, 40, 174-179.

46. Ochoa-Martínez, P.Y.; Hall-López, J.A.; Carmona-López, J.A.; Reyes Castro, Z.E.; Sáenz-López, P.; Conde-García, P. Análisis comparativo de un programa educación física en niños con discapacidad auditiva sobre la edad motora equivalente. Retos 2019, 35, 310-313.

47. Martins, P.; Rodrigues, H.; Rocha, T.; Francisco, M.; Morgado, L. Accessible options for deaf people in e-learning platforms: Technology solutions for sign language translation. Procedia Comput. Sci. 2015, 67, 263-272. [CrossRef]

48. Schultz, J.L.; Lieberman, L.J.; Ellis, M.K.; Hilgenbrinck, L.C. Ensuring the success of deaf students in inclusive physical education. J. Phys. Educ. Recreat. Danc. 2013, 84, 51-56. [CrossRef]

49. Reich, L.M.; Lavay, B. Physical education and sport adaptations for students who are hard of hearing. J. Phys. Educ. Recreat. Danc. 2009, 80, 38-49. [CrossRef]

50. Pivetta, E.; Saito, D.; Ulbricht, V. Deaf and Accessibility: Analysis of a Virtual Learning Environment. Revista Brasileira de Educação Especial. 2014, 20, 147-162. [CrossRef] 